\title{
$\mathrm{HPGe}$ 검출기에서 환경방사능측정의 검출하한치에 관한 연구
}

\author{
장은성
}

부산대학교 핵물리 및 방사선기술연구소

\section{A Study on Minimum Detection Limit of Environmental Radioactivity in HPGe Detector}

\author{
Eunsung Jang \\ Pusan National University Nuclear Physics and Radiation Technology Research Center
}

요야

검출한계에 대한 기본개념을 기초로 백그라운드 측정시간과 시료측정시간을 고려하였고, 환경시료중에서 육상 시료(하천토, 표층토양, 식수, 지하수, 지표수, 솔잎, 쑥) 분석에서 백그라운드 계측시간과 시료 측정시간의 변화에 따른 $\mathrm{MDA}$ 값들을 비교하였다.

물시료 분석결과를 살펴보면 대부분 시료에서 불검출로 나타났으며, 육상시료 분석결과 대부분의 시료에서 “ 과학기술부고시 제 2008-28호"의 검출하한치 미만으로 측정되었으나, 일부 시료에서는 인공방사성핵종인 ${ }^{137} \mathrm{Cs}$ 이 검출되었다. 이는 과거 50.60 년대 행해졌던 대기권 핵실험에 의한 낙진 및 소련의 체르노빌 원전사고 등에 의한 영 향으로 우리나라뿐만 아니라 전 세계적으로 검출되고 있는 수준이다. 또한 ${ }^{137} \mathrm{Cs}$ 의 동위원소이며, 상대적으로 반감 기가 짧은 ${ }^{134} \mathrm{Cs}$ 가 모든 시료에 대해서 검출되지 않는 것으로 보아 원전운영에 의한 영향이 아님을 알 수 있다.

중심단어 : 최소 감지 활동, 토양샘플, 인공방사능핵종, 감마 핵종분석기

\section{Abstract}

Based on basic concept of detection limit, sample measurement time \& background measurement time was considered, and MDA values according to background measurement time and sample measurement time in land samples(river soil, surface soil, drinking water, underground water, surface water, pine leaf, mugwort) analysis among environmental samples were compared.

Seeing the water sample analysis result, it was shown that most of the samples were not detected, and most of the samples in land specimen analysis showed to be below the detection limit of "Ministry of Education, Science and Technology Announcement Je-2008-28-ho", but ${ }^{137} \mathrm{Cs}$ which is one of artificial radioactive nuclide was detected in some samples. It can be traced back to 1950s and 1960s when nuclear tests were carried out in atmosphere and catastrophic Chernobyl atomic power station accident that caused fallouts in the sky, and this is common level of detection that can be observed worldwide. Seeing the result that the ${ }^{134} \mathrm{Cs}$ (which is a isotope of ${ }^{137} \mathrm{Cs}$, and it has relatively short half life) was not detected in all samples, it can 
be considered it doesn't affect to the operation of atomic power station.

Key words : Minimum Detectable Activity(MDA). soil sample. artificial radioactive nuclide. gamma nuclide analyzer

\section{I. 서 론}

저준위 방사능이 함유된 환경시료에서 방사능 계측 시 방사능붕괴와 백그라운드 계수치의 통계학적 요동 특성으로 인해 실제로 방사능이 존재하지 않은 시료 의 계수치가 백그라운드를 상회하는 경우가 종종 발 생한다. 따라서 저준위 환경방사능 농도 측정시 방사 능 조내 여부를 판단하는 근거로 계측 통계학을 기초 로 한 검출한계치( lower limits detection, LLD)를 정의 한다 $^{[1-12]}$. 그러나 검출한계치는 통계학만을 바탕으로 정의된 것이며 다른 우연오차라든지 계통오차는 고려 되지 않았으므로 방사선 계측기로 검출할 수 있는 절 대적인 방사능 준위로서가 아니라 다만 최소검출 방 사능 농도를 설정하기 위한규제 지침으로 사용된다. 또한 검출한 계치는 백그라운드 계수치와 검출효율과 같은 계측시스템 인자들만을 기초로 설정되었으므로 저준위 방사능 측정 결과에 대한 방사능 존재 여부를 신뢰성 있게 판단하기에는 부적합하다. 즉 검출한 계 치는 시료의 방사능 농도에 의존하지 않고 측정과정 자체의 검출능력에 의존하므로 실제 저준위 환경방사 능 분석에서는 검출한계치 대신에 최소검출 방사능 준위(minimum detectable activity level, $\mathrm{MDA}$ )를 많이 사 용한다 ${ }^{[13-19]}$.

$\mathrm{MDA}$ 는 주어진 기계, 분석방법 및 시료종류에 따라 실제로 얻어질 수 있는 방사능 농도준위로 방사능 측 정분야에서 많이 사용되는 용어다. $\mathrm{LLD}$ 는 측정한 계 측기의 특성인 백그라운드 계수치나 계측효율을 고 려하여 통계학적으로 산출된 값으로 분석화학에서 측 정된 분석결과에 대한 신뢰도 평가에 사용된다. $\mathrm{MDA}$ 는 LLD와 비교하면 약간 포괄적인 개념으로 LLD 산 출시 사용된 검출기의 특성( 백그라운드, 검출효율)뿐 만 아니라, 시료크기, 시료측정시간, 자기흡수, 화학수 율 및 방사능 농도결정에 영향을 주는 여러 요인들을 포함한다. 따라서 $\mathrm{MDA}$ 는 계측기 특성 뿐 아니라 계측 과정에 포함되는 많은 특수한 요인과 시료자체의 특
성에 따라 값이 변하기 때문에 분석방법을 개선하거 나 측정장비를 교환할 경우 $\mathrm{MDA}$ 값을다시 산출해야만 한다 19. 검출한계에 대한 기본개념을 기초로 백그라 운드 측정시간과 시료측정시간을 고려한 검출한계치 유도과정을 기술하였고, 환경시료중에서 육상시료(하 천토, 표층토양, 식수, 지하수, 지표수, 솔잎, 쑥) 분석 에서 백그라운드 계측시간과 시료 측정시간의 변화에 따른 $\mathrm{MDA}$ 값을 분석, 비교하였다.

\section{II. 실험방법}

\section{1. 시료채취 및 전처리}

\section{1 시료의 채취 및 선택}

환경방사선 정도를 정확하게 판단하기 위해서 시료 채취는 측정-분석 못지않게 중요하다. 시료는 대상 지역의 오염정도의 척도가 될 수 있어야 하고, 또한 지역과 계절의 특성과 무관해야 하며 시료의 채취 및 분석이 용이해야만 한다.

지점을 선택하는데 있어서 부지주변 뿐만 아니라 시설과 무관한 비교지점을 선택하여 해당 시설에 의 한 영향인지를 판단할 수 있어야 한다.

토양시료는 부지내 2 개소(정수장,전시관), 부지주변 8 개소(월 내,연산,사택2 단지,임랑,비학,서생, 일 광,길천) 그리고 비교지점인 울산에서 상-하반기에 2회 채취 하였다. 채취장소는 개방된 미경작지로 항상 훍면이 노출돼 있으며, 지표수 등의 유동에 의한 침식, 붕괴 및 인위적 변동이 없는 경사가 완만한 장소를 선정하 였다. 채취지점은 대표성을 유지하기 위해 반경 $5 \mathrm{~m}$ 내 에서 $500 \mathrm{~g}$ 이상을 토양채취기로 채취 - 혼합하여 그 지점의 시료로 사용하였다. 방사성 핵종의 깊이 침투 를 고려하여 표토 층으로 부터 $5 \mathrm{~cm}$ 이내의 토양을 채 취하였다. 하천토는 효암, 월내, 임랑 비교지점 울산에 서 매분기 시료를 채취하였다. 하천가에서 채취기를 
사용하여 강바닥을 긁어서 채취하였다. 육상물시료(식 수,지하수,지표수)에서 식수는 부지주변 3개소(신암,반 룡,길천)와 비교지점으로 울산에서 채취를 하였고, 지 하수. 지표수는 부지주변 2개소와 비교지점으로 울산 에서 채취하였다. 용기는 채취 전에 염산 $(1+1)$ 또는 질 산(1+1)으로 세척 후 증류수로 다시 세척한다. 시료 채 취는 채취한 물에 포함된 방사성핵종이 시료용기에 흡착되는 것을 방지하기 위하여 물 $1 \mathrm{~L}$ 당 염산 $(1+1)$ 또 는 질산 $(1+1) 2 \mathrm{~mL}$ 를 첨가하여 밀봉한다. 빗물은 관측 소와 사택 3 단지 비교지점인 부산대에 빗물 채집기를 설치하여 1 개월간의 빗물을 전량 채집하였다. 지표생 물로서 솔잎은 관측소를 비롯한 4 개 지점과 비교지점 인 울산에서, 그리고 쑥은 월내와 비교지점으로 울산 에서 4 월과 9 월에 채취를 하였다.

\section{2 시료의 전처리}

전처리의 목적은 원시료가 갖고 있는 방사성핵종의 손실 없이, 균질하게 농축하여 원시료의 부피를 줄이 는 것이다. 그 때문에 액체시료에서는 증발농축, 고체 시료와 생체시료는 건조, 분쇄 등의 방법을 사용하여 시료를 조제한다.

하천토 및 표층토양는 각 지점에서 채취한 토양은 스텐 바트에서 펼쳐 그늘진 곳에서 풍건한다. 풍건하 면서 나무뿌리나 불순물 등과 같은 이물질을 제거한 다. 건조중에 덩어리가 된 부분은 잘게 부수고, 건조 후 $2 \mathrm{~m}$ 체를 이용하여 위에서 제거하지 못한 $2 \mathrm{~m}$ 이상 의 이물질을 제거한다. 체로 거른 시료의 무게를 재고 측정용 용기인 $450 \mathrm{~mL}$ 마리넬리 비이커에 충진한 다음 측정시료의 무게를 재고 측정한다. 육상물시료(식수,지 하수,지표수)는 채취한 시료를 테프론 코팅용기(60L)에 담아서 $2 \mathrm{~L}$ 까지 증발 농축한 후 환경 방사능 표준 측정 용기인 마리넬리 비이커(2L)에 담아서 저준위 감마선 측정장치 $(\mathrm{HPGe})$ 를 이용하여 측정한다. 지표생물(솔잎, 쑥)은 채취한 시료를 흐르는 물에 깨끗이 섹척한 다음 식용부분만을 취하여 무게를 측정한 후 완전히 건조 시킨다. 건조된 시료의 질량을 측정하고 분쇄기를 이 용하여 분쇄한다. 분쇄한 시료를 $1 \mathrm{~L}$ 마리넬리 비이커 의 지시 선까지 채운 다음 무게를 재고 측정시료의 건 조 질량비를 구한 다음 감마동위원소분석기를 이용하 여 측정한다.

\section{3 시료의 방사능 농도 측정 및 최소검출농도 $(\mathrm{MDA})$ 설정}

측정시료는 분말 상태이며, 측정시료용기는 $450 \mathrm{~mL}$ 마리넬리 비이커의 표준용기를 이용하였다. 일반 환경 시료의 경우 매우 낮은 방사능을 갖기 때문에 보통 24 시간 이상의 측정시간을 갖는다. 감마핵종분석기( AMETEK ORTEC: EG\&G)는 HPGe 검출기( GC3020), 고전압공급기, 증폭기, 다중파고분석기, 컴퓨터 및 주 변기기로 구성되었다(Fig.1).

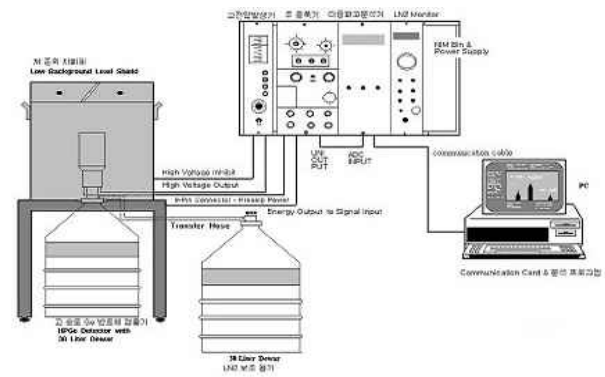

Fig.1. High Purity Germanium (HPGe) Gamma-ray spectroscopy system.

$\mathrm{HPGe}$ 검출기의 상대효율은 $30 \%$ 이며 에너지분해능 (FWHM)은 $60 \mathrm{Co}$ 핵종에서 방출되는 $1.33 \mathrm{MeV}$ 의 감마 선 에너지에 대하여 $1.78 \mathrm{keV}$ 이었다. 피크 대 컴프턴 (peak-to-compton)비는 각각 54/1 이다. 또한 교정용 혼 합표준선원을 이용하여 감마핵종분석기의 에너지 및 효율을 교정하였다. 본 연구에서는 아무런 시료도 넣 지 않은 백그라운드 측정시간을 80000 초로 하였으며 (Fig.2.)

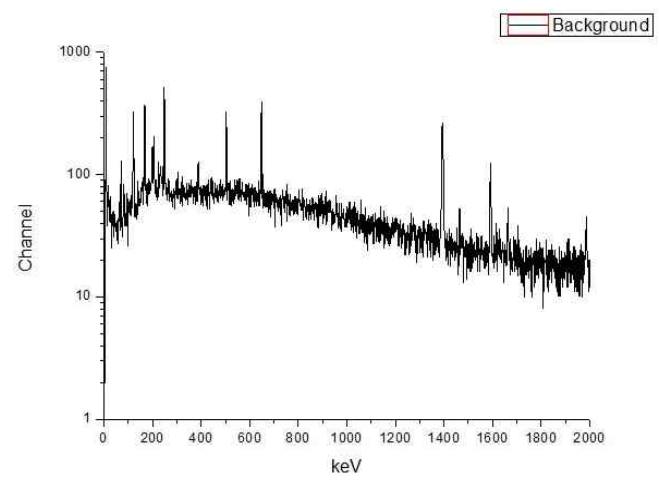

Fig. 2. The background spectrum obtained of 80000 s. 
시료의 측정시간을 400000 초로 하여 측정 하여 분 석 비교하였다(Fig.3)

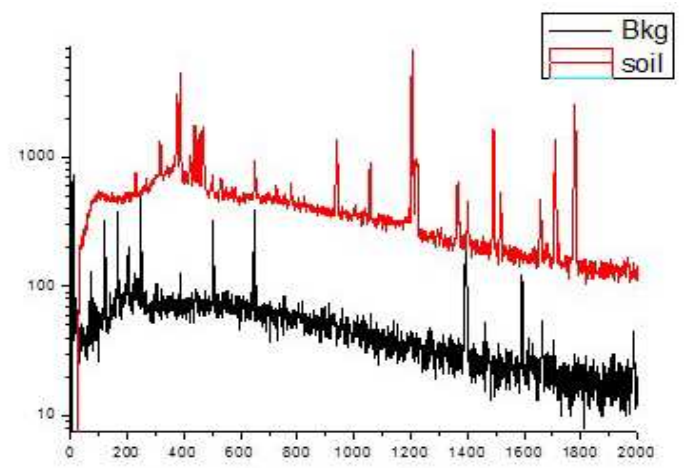

Fig.3. Comparison of background spectra with at water

정이 끝난 스펙트럼은 분석용 프로그램인 Gamma Vision(EG\&G ORTEC Co)을 이용 하여 분석하였다 (Fig.4)

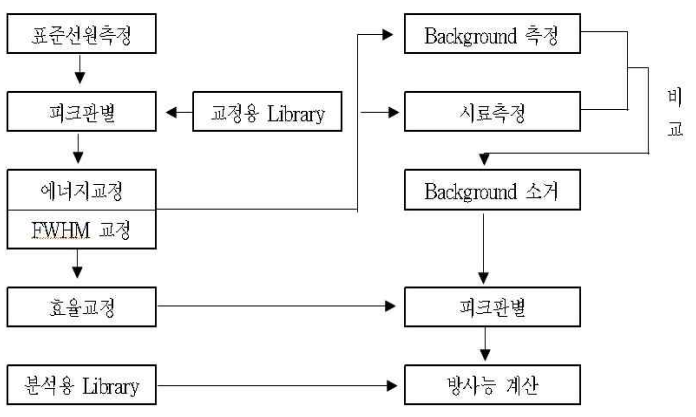

Fig.4. Gamma nuclide analyzer process.

\section{3 농도계산}

저준위 환경방사능 분석에서 의미 있는 $\mathrm{MDA}$ 값을 산출하기 위해서 신뢰도를 $95 \%$ 로 설정하여 $(\mathrm{Ka}=\mathrm{K} \beta$ $=\mathrm{K}=1.645)$ 최소 검출 방사능 농도를 계산한다. 환경시 료 중 최소검출 방사능 농도의 의미인 $\mathrm{MDA}$ 는 $\mathrm{LLD}$ 에 서 사용된 백그라운드 계수치와 계측시간 뿐만 아니 라 계측효율, 화학수율 및 시료량에 의존한다. 따라서 다음 식(1)과 같이 쓸 수 있다.

$$
\mathrm{MDA}_{1}=\frac{4.65 \sqrt{\mathrm{BGC}}}{\mathrm{t}_{\mathrm{B}} \cdot \mathrm{E} \cdot \mathrm{Y} \cdot \mathrm{S}}
$$

여기서 $\mathrm{BGC}$ 는 백그라운드 계수치, $\mathrm{ts}$ 는 시료 계측 시간, $\mathrm{tB}$ 는 백그라운드 계측시간, $\mu \mathrm{B}$ 는 백그라운드 계 수율, $\mathrm{Y}$ 는 화학수율, $\mathrm{S}$ 는 보정인자로 시료량과 측정 중 반감기를 보정하는 인자이다.

\section{4 검출기 교정 및 스펙트럼 분석}

방사성 핵종의 정확한 분석을 위해서는 장비의 정 확한 교정은 매우 필수적인 절차이다. 만약 측정 장비 의 교정이 이루어지지 않는다면 엉뚱한 결과를 얻게 될 수도 있다

그 중에서 검출효율은 측정시료와 동일한 물리적, 화학적 형태를 가진 표준선원을 이용하여 교정한. 표 준선원을 이용하여 측정한 고순도게르마늄 $(\mathrm{HPGe})$ 검 출기의 스펙트럼 형태의 결과는 Fig. 5 와 같다.

\section{III. 결과}

표층토양시료는 전 지점(12)에 대하여 분석결과 인 공방사성 핵종으로서 전 세계 토양시료에서 공통적으 로 측정되고 있는 ${ }^{137} \mathrm{Cs}$

이 검출되었다. 또한, 일반자연 중에 널리 존재하는 자연방사성 핵종 $40 \mathrm{~K}$ 이 검출되었다. 그 외의 인공방사 선 핵종은 검출되지 않았다(Fig.5.)

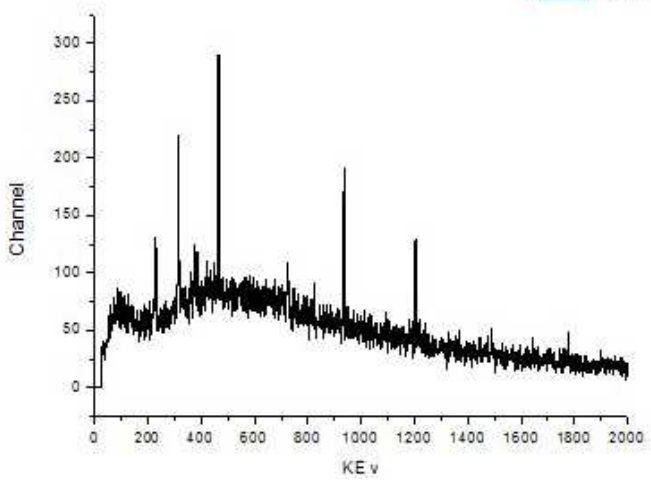

Fig.5. Gamma-ray spectrum of land specimen sample. 
표층토양 중에서 검출된 $137 \mathrm{Cs}$ 농도는 부지주변에서 $\ulcorner<\mathrm{MDA} \sim 16.0 \mathrm{~Bq} / \mathrm{kg}-\mathrm{dry}\lrcorner$ 로 검출되었으며, 비교 지점인 $\mathrm{A}$ 에서는 최대값 $\ulcorner 0.342 \mathrm{~Bq} / \mathrm{kg}$-dry $\lrcorner$ 로 검출되 었다(Table1.). 따라서 표층토양에서 측정된 ${ }^{137} \mathrm{Cs}$ 은 일 반지역에서도 널리 검출되고 있는 수준이고, 방출비가 비슷한 동위원소 ${ }^{134} \mathrm{Cs}$ 가 전혀 검출되지 않는 것으로 보아 원전 운영으로 인한 것이 아닌 과거 낙진에 의한 영향이다. 토양중의 ${ }^{137} \mathrm{Cs}$ 은 과거 1960년대 미국, 련, 중국 등에 의해 수행된 대기권 핵실험의 낙진에 의한 것이 대부분으로서, 30 년이 지난 오늘날에도 전 세계 적으로 지역적인 차이는 있지만 검출이 되고 있다. 또 한 토양의 경우 가장 많은 방사능을 차지하는 것으로 자연방사성 핵종인 $40 \mathrm{~K}$ 이 $\ulcorner 320 \sim 1020 \mathrm{~Bq} / \mathrm{kg}$-dry $\lrcorner$ 로 검출되었다. 하천토양(효암,월내,임랑)과 비교지점인 울산에서 매 분기 채취하여 분석한 결과 ${ }^{137} \mathrm{Cs}$ 이 부지 주변에서 $\ulcorner 0.369 \sim 1.85 \mathrm{~Bq} / \mathrm{kg}$-dry $\lrcorner$ 로 검출되었다. 이 는 위의 표층토양과 마찬가지로 과거 대기권 핵실험 의 결과이며, 전 세계적으로 일반토양에서 측정되고 있는 수준이다. 그 외의 인공방사성핵종은 검출되지 않았다. 식수 및 지하수는 매 분기마다 식수는 부지주 변 3 개소에서, 지하수는 부지주변 2 개소에서 채취하였 으며, 비교지점시료는 울산에서 채취하였다. 분석결과 모든 시료에 대하여 저준위 감마동위원소분석기를 이 용하여 측정하였는데(Fig.6), 모든 시료에서 검출하한치 미만(MDA)인 인공방사성핵종 $\left({ }^{131} \mathrm{I}\right)$ 은 검출되지 않았다.

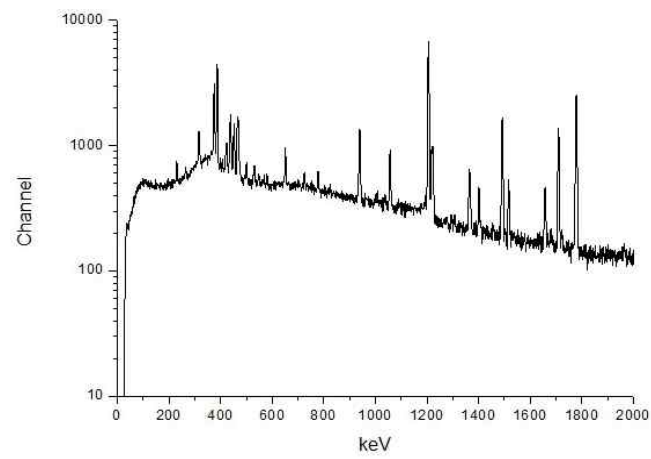

Fig. 6. Gamma-rat spectrum of water sample.

지표수 분석결과 인공방사성핵종 $\left({ }^{131} \mathrm{I}\right)$ 은 검출하한 치 미만으로 측정되었다(Table 1).

지표생물로서 솔잎은 4 개지점과 비교지점 울산에서
상.하반기 년 2회 채취하였으며, 쑥의 경우는 2 개지점 에서 채취결과 상.하반기 모두 인공방사성핵종 $\left({ }^{137} \mathrm{Cs}\right)$ 은 검출하한치 미만으로 측정되었다. 그 외 자연방사 성핵종인 $7 \mathrm{Be}, 40 \mathrm{~K}$ 이 검출되었다.

Table. 1. The land specimen of the radioactivity

\begin{tabular}{|c|c|c|c|c|c|}
\hline \multirow{2}{*}{$\begin{array}{l}\text { 채취 } \\
\text { 지점 }\end{array}$} & \multirow[b]{2}{*}{ 시기 } & \multicolumn{3}{|c|}{ 방 사 능 농 도 (Bg/kg.dry) } & \multirow{2}{*}{$\begin{array}{c}\text { Cs-137 } \\
\text { 평상준위(최 } \\
\text { 소 최대) }\end{array}$} \\
\hline & & Cs-134 & Cs -137 & $k-40$ & \\
\hline \multirow[t]{2}{*}{$B$} & 하반기 & 불검출 & $0.374 \pm 0.078$ & $9.17 \pm 18$ & \multirow{2}{*}{$0.469 \sim 1.26$} \\
\hline & 상반기 & 불검출 & $0.256 \pm 0.084$ & $920 \pm 19$ & \\
\hline \multirow[t]{2}{*}{ C } & 하반기 & 불검출 & $2.25 \pm 0.11$ & $705 \pm 14$ & \multirow{2}{*}{$1.41 \sim 7.37$} \\
\hline & 상반기 & 불검출 & $3.69 \pm 0.15$ & $704 \pm 15$ & \\
\hline \multirow[t]{2}{*}{ D } & 하반기 & 불검출 & $11.0 \pm 0.3$ & $638 \pm 13$ & \multirow{2}{*}{$0.0804 \sim 11$} \\
\hline & 상반기 & 불검출 & $4.85 \pm 0.18$ & $601 \pm 13$ & \\
\hline \multirow[t]{2}{*}{$\bar{E}$} & 하반기 & 불검출 & $11.1 \pm 0.3$ & $377 \pm 8$ & \multirow{2}{*}{$0490-25.2$} \\
\hline & 상반기 & 불검출 & $20.8 \pm 0.5$ & $416 \pm 9$ & \\
\hline \multirow[t]{2}{*}{$\bar{F}$} & 하반기 & 불검출 & $3.13 \pm 0.11$ & $727 \pm 15$ & \multirow{2}{*}{$0.25 \sim 25.6$} \\
\hline & 상반기 & 불검출 & $3.48 \pm 0.16$ & $601 \pm 13$ & \\
\hline \multirow[t]{2}{*}{ G } & 하반기 & 불검출 & $0.252 \pm 0.079$ & $724 \pm 15$ & \multirow{2}{*}{$1.90 \sim 23.3$} \\
\hline & 상반기 & 불검출 & $12.6 \pm 0.4$ & $604 \pm 13$ & \\
\hline \multirow[t]{2}{*}{$\mathrm{H}$} & 하반기 & 불검출 & $20.6 \pm 0.5$ & $479 \pm 10$ & \multirow{2}{*}{$0.25 \sim 22.5$} \\
\hline & 상반기 & 불검출 & $13.8 \pm 0.3$ & $476 \pm 10$ & \\
\hline \multirow[t]{2}{*}{ I } & 하반기 & 불검출 & $0.253 \pm 0.068$ & $381 \pm 8$ & \multirow{2}{*}{$0.440 \sim 16.2$} \\
\hline & 상반기 & 불검출 & $11.8 \pm 0.3$ & $475 \pm 11$ & \\
\hline \multirow[t]{2}{*}{ J } & 하반기 & 불검출 & $0.925 \pm 0.093$ & $559 \pm 12$ & \multirow{2}{*}{$0.563 \sim 20.8$} \\
\hline & 상반기 & 불검출 & $4.06 \pm 0.17$ & $425 \pm 9$ & \\
\hline \multirow[t]{2}{*}{ k } & 하반기 & 불검출 & $9.44 \pm 0.17$ & $608 \pm 12$ & \multirow{2}{*}{ 1.24 10.6 } \\
\hline & 상반기 & 불검출 & $0.429 \pm 0.23$ & $714 \pm 15$ & \\
\hline \multirow[b]{2}{*}{$\mathrm{H}$} & 하반기 & 불검출 & $1.6 \pm 0.10$ & $601 \pm 13$ & \multirow{2}{*}{ 2. 17 21.1 } \\
\hline & 상반기 & 불검출 & $6.49 \pm 0.25$ & $508 \pm 11$ & \\
\hline
\end{tabular}

\section{IV. 결론}

저준위 환경방사능 분석에서는 백그라운드 측정시 간, 시료측정시간, 백그라운드 계수율, 계측효율, 화학 수율 및 시료량등의 여러인자가 $\mathrm{MDA}$ 값 설정에 영향 을 미치는데 그 중에서 분석시료량의 증가가 $\mathrm{MDA}$ 값 을 낮추는데 가장 효과적이다. 그러나 시료 량을 무조 건 늘릴 경우 핵종 분석 소요시간도 증감을 고려해야 한다. 또한 백그라운드 및 시료계측시간을 무한정 길 게 설정할 경우 $\mathrm{MDA}$ 값은 낮게 계산되지만 분석소요 시간 증가된다. 물 시료 분석결과를 살펴보면 대부분 시료에서 불검출로 나타났으며, 육상시료 분석결과 대 부분의 시료에서 “ 과학기술부고시 제 2008-28호”의 검 출하한치 미만으로 측정되었으나, 일부 시료에서는 인 공방사선핵종인 ${ }^{137} \mathrm{Cs}$ 의 동위원소이며, 상대적으로 반 
감기가 짧은 ${ }^{134} \mathrm{Cs}$ 가 모든 시료에 대해서 검출되지 않 는 것으로 보아 원전운영에 의한 영향이 아님을 알 수 있다 ${ }^{[20],[21]}$.

\section{감사의 글}

첨단융합신물질물리 특성화사업단의 지원과 한국기 초과학지원연구원 부산센터의 원소함량 분석 지원에 대하여 감사드립니다.

\section{참고 문헌}

[1] B.Altschuler and B. Pasternak, health Physics, Vol 9, pp 293-298, 1963

[2] L.A. Currie, Anal, Chem, Vol 4,, pp 586-593, 1968

[3] B.S. Pusternack and N.H. Harley, Nucl. Instr and Meth, Vol 91, pp $553-540,1971$

[4] J. H. Head, Nucl. Instr and Meth,Vol 98, pp 419-428, 1972

[5] H.F show and L.A. Joseph, health Physics, Vol 92, pp 282-285, 1977

[6] J.D. Jack and L.W. Robert, Health Physics, Vol 32, pp 1-14, 1977

[7] U.S. Environmental Protection Agency(EPA), "Upgrading environmental radiation data", Heath Physics Society Committee Repoty-1, Washington D.C. U.S.A., 1980.

[8] J.A.Roderick, Health Physics, Vol 42, pp 230-231, 1982

[9] J.A.Roderick, Health Physics, Vol 43, pp 693-7031, 1982

[10] National Council on Radiation Protection and Measurement(NCRP), "A handbook of radioactivity measurements procedure", Bethesda, MD,NCRP Report No 58, 1985.

[11] A. Brodsky, R.G. Gallaghar, Radiat. Protect. Mgt,. Vol 8, pp 64-78, 1991.

[12] H. Friedmann,, Health Physics, Vol 77, pp 309-312, 1999.

[13] R. Seymour, F. Sergent, K.Knight and B Kyker. Radioactivity \& Radiochemistry, Vol 3, pp 14-28, 1992

[14] A.C. Donald, S.D. Stephanie and L.S. Edwin, Health Physics. Vol 63, pp 338-340, 1992.

[15] J.S. Daniel and S.S.Paul, Health Physics, Vol 63, pp 360-361, 1992.

[16] D.Mayer and L. Dauer, Health Physics,Vol 65, pp 89-91, 1993.
[17] 이재기,“ 환경방사능 감시 워크샆: 환경방사능 검출 한계에 대한 과찰”, 한국원자력안전기술원, 1996.

[18] F.M. Cox and C.F. Guenther, Health Physics, Vol 69, pp 121-129, 1995.

[19] 이명호, 신현상,홍광희,저영현,이창우, 대한방사선방어학회, Vol 24, pp 171-184, 1999.

[20] 한국원자력안전기술원, 원자력시설주변 환경조사 및 평가보고서, KINS/AR-730, 2008

[21] 한국원자력안전기술원, 전국환경방사능조사, Vol 31, pp KINS/AR-409, 2008 